"...on the menu of lifelong learning
the meeting looked for a time to be the
starter that no one much had a taste
for anymore..."

\title{
Not so splendid isolation
}

It's official, summer is out; the cover date of this issue coincides with that of the autumn equinox. Many aspects of the British way of life are influenced by, or given guidance through, the changing seasons. Of course the overlap of supposed seasonal conditions, the state of the weather and the chronology of dates is hardly a precise science. How often is it pointed out that midsummer's day on 24 June falls just three days after the official start of that season? And how often do we then quip that a summer of six days is about right in Britain? But what else could we talk about in the absence of uncertain weather? Well in our case, plaque of course, or caries, or matrix bands, but in the generality, very little.

For all the speculation on global warming, or not, September gradually marks the transition from a warmer to a cooler time. It is a return to pleasantly being able to reach for that comforting old friend of a jumper, to closing the windows a little further in, to listening out for the hum of the boiler and the gentle ping of a reblushing radiator. It also marks the start of a period that is often referred to as one of increased 'association'. Speakers, organisers, meeting secretaries, caterers and printers of programmes will confirm that the next few months constitute one of their busiest seasons, irrespective of the weather. Bluntly put, it is about getting together again.

Dentistry is an isolated profession and can also be a lonely, or perhaps that should be lonesome one. Even in practices of more than one dentist much of the working time is concentrated with self-absorption in often physically confining surroundings. Yet one of the factors frequently expressed as being a benefit of being a dentist is the opportunity to move in professional circles with colleagues and to participate in discussion and study groups.

The abundance of meetings, lectures, seminars, conferences and exhibitions taking place in the coming weeks and months provides the opportunity to come out of the self-confined limits of our individual surgeries and practices and meet other people. They may predominantly be colleagues, other dentists, increasingly other dental care professionals but the important aspect is that it allows us to discover that we are not the only ones to be facing whatever problems have been vexing us. Sharing what turn out to be common experiences and feelings is wonderful therapy. Casting no aspersions on the quality of any of this season's speakers, it is often said that the value of a meeting is to be found not in the content of the presentation but in the quality of conversation in the tea break, the lunch queue, the coffee and Danish interlude. Why so? Because it is then that the conversations about how it really is 'out there' kick in. What a relief to know you're not unique, at least in this.

Making excuses is easy, always easier then taking action. "It's been a long day. I'm tired. I already know everything that the lecture's to be about. I just can't be bothered to drive there". Indeed, on the menu of lifelong learning the meeting looked for a time to have met its match, to be rather old fashioned. It was the starter that no one much had a taste for anymore, the main course that was so last century now that the tantalising dessert trolley of the Internet had glided amongst us.

The advent of distance learning is certainly to be welcomed and has many advantages, the most obvious of which is also its largest disadvantage, namely the ability of being able to learn and study in the comfort of your own home or practice. Where, guess what, you are by yourself again. As a dish in the sedentary feast of professional updating it has a worthy place on the table but as a vehicle for socialisation it is a poor cousin to the reality of mixing with people with similar interests, backgrounds and insecurities. Make no mistake we live in uncertain, if exciting, times and the ability to share is also the ability to progress.

Shakespeare understood the power of the changing year, "how many things by season, seasoned are" he muses in The Merchant of Venice. Take up that power as we head back into the period of creeping mists, mellow fruitfulness and long, dark evenings. Get out and meet some folks. Splendid isolation is a term born of irony, for there is nothing splendid about staying professionally alone.

Stephen Hancocks OBE, Editor in Chief doi: $10.1038 /$ sj.bdj.4814075 